\title{
Dysregulation of Zinc and Iron Balance in Adipose Tissue from Diabetic Sand Rats (Psammomys obesus)
}

Trine Maxel ${ }^{1}$, Rasmus Pold ${ }^{2}$, Agnete Larsen ${ }^{1 *}$, Steen Bønløkke Pedersen ${ }^{3}$, Dorthe Carlson ${ }^{4}$, Bidda Rolin $^{5}$, Thóra Brynja Bödvarsdóttir ${ }^{5}$, Sten Lund $^{2}$, Jørgen Rungby ${ }^{1,6}$ and Kamille Smidt ${ }^{1}$

${ }^{1}$ Department of Biomedicine, Aarhus University, Wilhelm Meyers Allé 4, 8000 Aarhus, Denmark

${ }^{2}$ Department of Clinical Medicine - The Department of Endocrinology and Diabetes, Aarhus University Hospital, Nørrebrogade 44, 8000 Aarhus, Denmark

${ }^{3}$ Department of Endocrinology (MEA), Aarhus University Hospital, Tage Hansens Gade 2, 8000 Aarhus, Denmark

${ }^{4}$ Department of Animal Science, Aarhus University, Blichers Allé 20, 8830 Tjele, Denmark

${ }^{5}$ Diabetes and Obesity Pharmacology Novo Nordisk A/S, Maaloev Byvej 200, 2760 Maaloev, Denmark

${ }^{6}$ Center for Diabetes Research, Department of Med F, Gentofte University Hospital, N. Andersens Vej 65, 2900 Hellerup, Denmark

\begin{abstract}
Background: In obesity, the distribution and metabolic function of adipose tissue are of vast importance for the risk of type 2 diabetes development. The homeostasis of zinc and iron is believed to be disturbed in diabetic patients. Zinc dyshomeostasis could affect the metabolic function of adipose tissue as zinc is known to facilitate the functions of insulin within adipose tissue as well as take part in cell proliferation and apoptosis. Further, altered iron levels have been shown to affect insulin sensitivity. This study investigates the intracellular zinc regulation and total zinc and iron status in adipose tissues in obesity-linked, type 2 diabetes in the Psammomys obesus model.
\end{abstract}

Methods: Subcutaneous and visceral adipose tissue were collected from diabetic $(n=6)$ and non-diabetic animals $(n=6)$. Total zinc and iron levels were analyzed by induced-coupled plasma mass spectrometry. Gene expressions of zinc transporters of the SLC30A and SLC39A family, regulating the intracellular zinc distribution, as well as several metabolic markers were investigated by RealTime-PCR.

Results: Diabetic animals exhibited signs of an altered zinc homeostasis i.e. a re-distribution of total zinc within visceral adipose tissues and altered transcription of zinc regulatory proteins ZIP6, ZIP8, ZIP9, and ZnT9. Further, diabetic animals displayed an iron accumulation in visceral adipose tissue that was positively correlated with insulin degrading enzyme and peroxisome proliferator-activated receptor gamma.

Conclusion: Psammomys obesus, a complex animal model of diet-induced type 2 diabetes, exhibits changes in the mineral status of zinc and iron in visceral adipose tissue. These changes might be related to the altered insulin sensitivity and metabolic function of visceral adipose tissue seen in type 2 diabetes. This study warrants further investigations into the role minerals, especially zinc and iron, play in the pathophysiology of type 2 diabetes.

Keywords: Adipose tissue; Iron homeostasis; Type 2 diabetes; Psammomys obesus; Peroxisome proliferator-activated receptor gamma; Zinc homeostasis; ZIP 14

Abbreviations: T2D: Type 2 Diabetes; P. obesus: Psammomys obesus; HSL: Hormone Sensitive Lipase; LPL: Lipoprotein Lipase; IDE: Insulin Degrading Enzyme; PPAR $\gamma$ : Peroxisome Proliferator-activated Receptor Gamma

\section{Introduction}

Type 2 diabetes (T2D) is a potential consequence of obesity affecting up to $20 \%$ of all obese individuals [1]. The distribution of fat in the body is important for the incidence of T2D since subcutaneous adipose tissue and visceral adipose tissue have different structural and metabolic characteristics $[2,3]$. Visceral adipose tissue shows a higher level of basal lipolysis, an accelerated response to lipolytic hormones, and a decreased response to the inhibitory effect of insulin on lipolysis. This metabolic characteristic of visceral adipose tissue results in an enlarged flooding of free fatty acids directly to the liver, through the portal vein, and thereby an increased gluconeogenesis. Furthermore, ectopic triglyceride accumulation occurs in muscle and pancreas. The result is peripheral insulin resistance and beta-cell dysfunction [2].

Overweight and obese individuals show altered levels of many essential trace elements in the blood $[4,5]$. The same pattern is found in type 2 diabetic individuals [6]. These alterations in trace element status have been associated with diverse metabolic changes [4,6-8]. Especially the disturbances in iron and zinc homesostasis have been in focus.
Zinc is an important mineral as it mimics and amplifies the pancreatic and peripheral functions of insulin. Furthermore, alterations in zinc balance are related to T2D [9-13]. Zinc permits the formation of insulin-hexamers in beta-cells and in part regulates the beta-cell mass [14-16]. In other insulin responsive tissues i.e. muscle and fat, zinc shows many insulinomimetic properties by affecting the insulinreceptor signal transduction $[13,17]$.

Zinc deficiency has been associated with increased levels of glycated hemoglobin in patients with T2D [6]. In obese individuals, zinc deficiency has also been associated with an aggravated lipid profile, increased glucose, and insulin levels $[7,18]$. Epidemiological studies indicate a relationship between zinc deficiency and an increased frequency of obesity [4]. In addition, obesity and T2D have been linked

*Corresponding author: Agnete Larsen, Department of Biomedicine, Wilhelm Meyers Allé 4, 8000 Aarhus, Denmark, Tel: +45 20282646; Fax: +45 86128316; E-mail: al@biomed.au.dk

Received October 27, 2014; Accepted January 22, 2015; Published January 31 2015

Citation: Maxel T, Pold R, Larsen A, Pedersen SB, Carlson D, et al. (2015) Dysregulation of Zinc and Iron Balance in Adipose Tissue from Diabetic Sand Rats (Psammomys obesus). J Diabetes Metab 6: 497. doi:10.4172/2155-6156.1000497

Copyright: ( 2015 Maxel T, et al. This is an open-access article distributed under the terms of the Creative Commons Attribution License, which permits unrestricted use, distribution, and reproduction in any medium, provided the original author and source are credited. 
to alterations in the zinc transporters, which control intracellular zinc balance. During the last decade, thorough investigation of the insulingranule localized $\mathrm{ZnT}$, has elucidated the importance of $\mathrm{ZnT8}$ in the supply of zinc to the crystallization, processing, and secretion of insulin $[19,20]$. A common genetic variant of ZnT8 has then proven to increase the risk of developing T2D [21]. On the contrary, a recent study investigating around 150.000 people found that loss-of-function mutations in the gene coding for the zinc transporter ZnT8 protects against the development of T2D [22]. A potential explanation of this paradoxical finding is the complementary role of other zinc transporters such as ZnT3 and ZnT7 in diabetes development [23,24].

Two families of solute-linked zinc transporter families are known: The zinc transporters (ZnT or Slc30a) responsible for zinc efflux and the ZRT/IRT-related proteins (ZIP or Slc39a) facilitating zinc influx $[25,26]$. In addition, at least three members of the ZIP family are able to transport other minerals. Transport of $\mathrm{Mn}^{2+}$ has been shown for ZIP7, ZIP8 and ZIP14, Cd ${ }^{2+}$ transport for ZIP8 and ZIP14 [27-29]. Furthermore, ZIP14 has been shown to play an essential role in iron transport and homeostasis [30].

Although most research on the regulation of intracellular zinc homeostasis in obesity and diabetes has been focused on the role of zinc in beta-cells, we have previously shown that in adipose tissue, the gene expression of several zinc transporters differ in obese individuals compared to their lean counterparts. Consistent transcriptional down-regulations were seen in visceral adipose tissue compared with subcutaneous adipose tissue and in obese individuals compared with lean individuals. This suggests that both obesity and differences in metabolic activity of various adipose tissues regulate the zinc transporters and thereby the intracellular zinc environment [31]. To what extent, intracellular zinc regulation is affected in adipose tissue during diabetes is so far not known.

Like zinc, disturbances in iron homeostasis have been connected to the pathogenesis of T2D. Dietary iron deficiency has been linked to obesity, whereas various forms of iron overload have been linked to the development of diabetes [32,33]. High fat diet can reduce iron uptake in the gut [34]. It has also been speculated that obesity-induced inflammation increases the level of hepcidin in this way leading to reduced dietary iron uptake [8]. Furthermore - as described in a recent review by Becker and co-workers [35] - an increased hepcidin expression could result in reduced iron absorption on the cellular level. In macrophages, such sequestering of iron could lead to anemia and other adverse physiological effects seen in obesity $[4,35]$. Paradoxically, hepcidin levels also rise in dietary iron overload. This means that cellular or tissue specific iron deficiency can be present despite a total body over-load potentially participating in the development of disturbances in adipocytes or beta-cells $[8,36,37]$. In disease related iron accumulation such as hemochromotosis and dietary iron overload have been linked to a higher risk of diabetes and beta-cell failure. In rodent studies, reduction of iron levels through phlebotomy or low iron diet has been shown to improve insulin secretion and insulin levels in both hemochromatosis and dietary overload [8].

Several studies focus on the role of micronutrients, e.q. zinc and iron, in relation to glucose metabolism and diabetes. Less is known about how micronutrient status affects adipocytes. It has been shown that iron status can affect adipokine regulation hereby potentially affecting lipid metabolism [8]. At present, the micronutrient status and regulation in adipose tissue are thus far from unraveled. Iron and zinc share several co-transport mechanisms including DMT and ZIP14 $[38,39]$ but are seldom investigated together.

The aims of this study were thus: to establish zinc and iron status in adipose tissue of diabetic Israeli sand rats, Psammomys obesus $(P$. obesus), and investigate if intracellular zinc regulation in adipose tissue is changed by the development of high energy diet- induced T2D, correlating gene expression of zinc regulatory proteins - including the zinc and iron transporter ZIP14- with mineral status and gene expression of key markers of adipocyte proliferation and glucose metabolism.

\section{Materials and Methods}

\section{Animals}

P. obesus were purchased from Harlan Laboratories, Jerusalem, Israel. The gerbils were ten weeks of age at the time of the acclimatization start. The animals were supplied with water ad libitum and maintained on a 12 -h dark-light cycle in a $25^{\circ} \mathrm{C}$ environment. Principles of laboratory animal care were followed and study approval was obtained from the Animal Experiments Inspectorate, Ministry of Justice. Diabetes prone animals, confirmed by their blood glucose levels on high- energy diet (Formulab Diet 5008, $3.5 \mathrm{kcal} / \mathrm{g}$, Harlan Teklad), were chosen for this experiment and put on high-energy diet for 5 weeks in order to develop T2D $(n=6)$. Diabetic animals were compared with diabetes resistant control animals on low-energy diet (3084-111507, $2.5 \mathrm{kcal} / \mathrm{g}$, Harlan Teklad) $(\mathrm{n}=6)$. The following tissues were dissected immediately after cervical dislocation in isoflurane anesthesia: Subcutaneous adipose tissue, retroperitoneal adipose tissue and epididymal adipose tissue. Both retroperitoneal and epididymal adipose tissue were considered visceral adipose tissue.

\section{Measurements of trace elements}

20-200 mg of adipose tissue was used for analysis. Samples were processed and mineralized in a Multiwave 3000 (Anton Paar) by a standard method (Bovine Liver) using $5.5 \mathrm{ml}$ nitric acid and $0.5 \mathrm{ml}$ hydrochloric acid. The samples were transferred to plastic tubes by several rinsing procedures in de-ionized pure water. Total zinc $(\mathrm{Zn})$, iron $(\mathrm{Fe})$, and copper $(\mathrm{Cu})$ levels as well as the $\mathrm{Cu} / \mathrm{Zn}$ ratio were determined in all three adipose tissues by Inductively coupled plasma mass spectrometry (ICP-MS) on an X series ${ }^{\mathrm{II}} \mathrm{ICP}-\mathrm{MS}$ equipped with a conventional Mainhard nebulizer and a Peltier cooled quartz impact bead spray chamber operated at $3^{\circ} \mathrm{C}$ (Thermo Electron Cooperation, Bremen, Germany) equipped with a CETAC autosampler model ASX520. Two samples from subcutaneous adipose tissue were excluded due to technical failure $(\mathrm{n}=5$ for both diabetic and control animals of subcutaneous adipose tissue, $\mathrm{n}=6$ for both diabetic and non-diabetic animals of retroperitoneal and epididymal adipose tissue). The accuracy and precision of the analytical procedures for metal levels in adipose tissue were assessed with a simultaneous analysis of a standard reference.

\section{RNA extraction and cDNA synthesis}

RNA purification of all tissue was performed using TRIzol (Invitrogen) according to the manufacturer's instructions. 100-200 mg of adipose tissue was used. The integrity of the RNA was confirmed by visual inspection of the two ribosomal RNAs on an ethidium bromide stained agarose gel. The concentration of the purified total RNA was determined spectrophotometrically by the A260/A280 ratio. $450 \mathrm{ng}$ of RNA were reverse transcribed into cDNA using the ImProm-IITM Reverse Transcription System (Promega, Denmark). The cDNA was 
Citation: Maxel T, Pold R, Larsen A, Pedersen SB, Carlson D, et al. (2015) Dysregulation of Zinc and Iron Balance in Adipose Tissue from Diabetic Sand Rats (Psammomys obesus). J Diabetes Metab 6: 497. doi:10.4172/2155-6156.1000497

Page 3 of 11

checked for genomic DNA contamination by PCR analysis using the Qiagen HotStarTaq Master Mix Kit (VWR, Denmark) with an intronspanning primer-set of $\beta$-actin (TAC, Copenhagen)

\section{Primer design and selected genes}

The genome of $P$. obesus is still to be sequenced, but by aligning homologous cDNA sequences from rat, mice, and human we managed to design specific primers for $P$. obesus. The specific primers were designed for $P$. obesus using www.ncbi.nlm.nih.gov. The specific genes of Mus musculus, Rattus norvegicus, and Homo sapiens were compared and similar regions were identified to predict the gene sequence of $P$. obesus (Table 1).

We were able to construct primers for the investigation of the gene expression of ZnT1, ZnT6, ZnT7, ZnT9, ZIP3, ZIP6, ZIP8, ZIP9, ZIP11, ZIP13, and ZIP14. In addition, the gene expression of Hormone sensitive lipase (HSL) and lipoprotein lipase (LPL) were investigated as indicators of lipid metabolism. The gene expression of insulin degrading enzyme (IDE) was measured as representative of the glucose metabolism alongside the transcription of two main adipocyte markers, peroxisome proliferator-activated receptor gamma (PPAR $\gamma)$ and leptin.

\section{Real-time PCR}

Quantitative real-time PCR was performed in duplicate with IQ Sybr Green supermix (Bio-rad, Denmark) in a MyiQ SingleColor Real-time PCR detection system (Bio-Rad, Denmark). For all reactions a melting curve was included. The results were analysed with $\mathrm{iQ}^{\mathrm{TM}} 5$ Optical System Software, Version 2.0. Starting quantities were calculated from a standard curve. Values were normalised to the geometric of three house-keeping genes [40,41].

\section{Determination of stable housekeeping genes}

The GeNorm method was used to determine the stability of the house keeping genes [41]. All housekeeping genes used in this study were stably expressed according to GeNorm analyses performed on our samples.

\section{Statistical analysis}

Real-time PCR data are given as mean starting quantity of (gene of interest/geometric mean of three housekeeping genes) \pm SEM and trace element measurements as mean value $\pm \mathrm{SD}$. The statistical package GraphPad prism 5 was used. Statistical analyses on the PCR results were done on log-transformed data to obtain normal distribution. Unpaired T-test was used to detect statistical significance when diabetic and non-diabetic $P$. obesus were compared followed by Welch's correction when needed. One-way repeated measurements analysis of variance (ANOVA) was used to detect statistically significant differences when comparing the three adipose tissues in diabetic $P$. obesus or non-diabetic $P$. obesus. Bonferronis post-test was used following a significant one-way ANOVA analysis. The levels of trace elements were analysed non-parametrically as data were not normally distributed. Mann Whitney test was used when comparing diabetic animals with non-diabetic animals whereas Kruskal-Wallis test followed by Dunn's Multiple Comparison Test was used when comparing the three different kinds of adipose tissue. Mean differences (mean diff) are given with a $95 \%$ confidence interval. A standard pearson correlation was used as a measurement of a possible linear correlation between the investigated parameters. Pearsons r-value, indicating the strength of the correlation, as well as the $\mathrm{p}$-value, are given. A p-value $<0.05$ was considered significant.

\section{Results}

\section{Blood glucose and $\mathrm{HbA1c} \%$ levels confirmed that high-energy diet induced T2D in the diabetes prone animals}

We investigated 6 diabetic animals (diabetes prone) after 5 weeks on high-energy diet. As controls we included 6 non-diabetic animals (diabetes resistant) that were kept on their natural low-energy diet throughout the experiment. The diabetic animals showed increased non-fasting blood glucose levels compared with non-diabetic animals [p<0.001, mean diff: 20.67, 95\%CI $(14.46 ; 26.87)$ ], mean non-diabetic: $3.45 \pm 0.18 \mathrm{mmol} / \mathrm{L}$, mean diabetic: $24.12 \pm 2.78 \mathrm{mmol} / \mathrm{L}]$. A blood glucose level of $>10 \mathrm{mmol} / \mathrm{L}$ was considered indicative of diabetes. An increase in $\mathrm{HbAlc} \%$ level was seen in the diabetic animals before and after the experiment $[\mathrm{p}=0.0234$, mean diff: $0.73,95 \% \mathrm{CI}(0.12 ; 1.34)$, mean before: $7.29 \pm 0.19 \%$, mean after: $8.02 \pm 0.20 \%]$.

\begin{tabular}{|c|c|}
\hline Cyclophilin A & F: 5' AGG TCC TGG CAT CTT GTC CA 3'. R: 5'CTT GCT GGT CTT GCC ATT CC 3'. \\
\hline Bactin & F: 5'CTA CAA TGA GCT GCG TGT GGC 3'. R: 5'ATC CAG ACG CAG GAT GGC ATG 3'. \\
\hline$H S P$ & F: 5' GAT TGA CAT CAT CCC CAA CC 3’'R: 5'CTG CTC ATC ATC GTT GTG CT 3'. \\
\hline ZnT1 & F: 5’ TGC TGT GCA TGC TGC TGC TG 3'. R: 5'GCG GAT CCA GCC GAA CGT GTT 3'. \\
\hline ZnT6 & F: 5' GCC CTG ATG ACG TTT GGC ACC 3'. R: 5'TGC ACT GAC CCA GCC AAT GAG C 3'. \\
\hline$Z n T 7$ & F: 5’ TCC CCA GTG CTA TCA GAG GGT GC 3'. R: 5’GCT GTC TCA CTC CAG CCT GAG T 3'. \\
\hline ZnT9 & F: 5’ AAG GGA CCA GGA AAA GTG GT 3'. R: 5'TAC GGG TGA GAA GGA TCT GG 3'. \\
\hline ZIP3 & F: 5' GAA GGC GCA CCG CTC CAA GA 3'. R: 5' TCA GCA CCA GCT GCT CCA CG 3'. \\
\hline ZIP6 & F: 5’ GGG CGA CGG GCT GCA CAA TT 3'. R: 5' GGC CAA CAT GGC TGA CAG AGC 3’. \\
\hline ZIP8 & F: 5' GGG GCT CAG TAC GTC CAT AGC GA 3'. R: 5' ACA TGC CTC CAG CGA GTG CA 3'. \\
\hline ZIP9 & F: 5' GCT GGC CTG GAG CGG AAT CG 3'. R: 5' GGG AGG ACA TGG ACG GTG GC 3'. \\
\hline ZIP11 & F: 5' CAG AGG GTC TTG CTG TTG GCG T 3'. R: 5' CCA TGC CGC TCA GCT GTC CA 3'. \\
\hline ZIP13 & F: 5’ ACT CAT GGG CTG GCT GTG GC 3’. R: 5’ GGC AAA GCA GGC CCC CAG AA 3’. \\
\hline ZIP14 & F: 5' CCC TGA GCG ATG GGC TCC ACA 3'. R: 5' TAG CAG CAG CAG GCA GAG AGG A 3'. \\
\hline PPARY & F: 5’ CGC ACT GGA ACT AGA TGA CA 3’. R: 5’ GGT GAA GGC TCA TGT CCG TC 3’. \\
\hline LPL & F: 5' CCA GCT GGA CCT AAC TTT GAG 3'. R: 5' CCT CCA TTG GGG TAA ATG TC 3'. \\
\hline HSL & F: 5’ GGC TTT GTG GCA CAG ACC TC 3’. R: 5' CCA GGA AGG AGT TGA GCC AT 3’. \\
\hline Leptin & F: 5' TCG CGG TCT ACC AAC ACA TC 3'. R: 5' TCT CTA GGT CGT TGG ATA TTT GCA 3’. \\
\hline IDE & F: 5' GCA GCC TCA CCA GCA TGC CA 3'. R: 5' ACT CCT AAG GCA GCC TGC TTG G 3'. \\
\hline
\end{tabular}

Table 1: Primers designed for $P$. obesus. Forward and reverse primer sequences. 
Citation: Maxel T, Pold R, Larsen A, Pedersen SB, Carlson D, et al. (2015) Dysregulation of Zinc and Iron Balance in Adipose Tissue from Diabetic Sand Rats (Psammomys obesus). J Diabetes Metab 6: 497. doi:10.4172/2155-6156.1000497

Page 4 of 11

In diabetic animals, an altered distribution of zinc was seen between visceral adipose tissues. The $\mathrm{Zn} / \mathrm{Cu}$ ratio was however not affected

Comparing diabetic and non-diabetic animals, indications of a reduced zinc content $(\mathrm{p}=0.09)$ were seen only in epididymal adipose tissue, whereas no signs of differences were found in retroperitoneal or subcutaneous adipose tissue (Figure 1).

Comparing the distribution of zinc among different adipose tissues, differences were seen comparing diabetic and non-diabetic animals. A significant difference was thus seen between epididymal adipose tissue and retroperitoneal adipose tissue $(\mathrm{p}=0.006)$ in the diabetic animals, with a higher level of zinc in retroperitoneal adipose tissue. The nondiabetic animals on the other hand, displayed no significant differences in the zinc levels when comparing the three different adipose tissues.

Calculations of the $\mathrm{Cu} / \mathrm{Zn}$ ratio showed no alterations between diabetic and non-diabetic animals or between the different kinds of adipose tissue.

In conclusion, T2D induction affected the distribution of zinc between the two visceral adipose depots: epididymal adipose tissue and retroperitoneal adipose tissue.
An accumulation of iron was found in epididymal adipose tissue in diabetic animals

An accumulation of iron was found in epididymal adipose tissue upon T2D development as diabetic animals had a significantly higher Fe content in epididymal adipose tissue compared to non-diabetic animals $(\mathrm{p}=0.0152)$.

Quantities of the $\mathrm{Zn}, \mathrm{Fe}$ and the $\mathrm{Cu} / \mathrm{Zn}$ ratio are shown in Table 2.

\section{Altered transcriptional regulations of zinc transporters were found in visceral adipose tissue from diabetic animals}

Distinct T2D-induced changes in the gene expression of zinc transporters of the $\mathrm{ZnT}$ and ZIP families were seen in visceral adipose tissue. In retroperitoneal adipose tissue, $Z n T 9(\mathrm{p}=0.0161), Z I P 8(\mathrm{p}<$ $0.0001)$, and $Z I P 9(\mathrm{p}=0.0036)$ were all transcriptionally down-regulated in diabetic animals compared with non-diabetic counterparts, whereas ZIP6 gene expression was up-regulated in both retroperitoneal adipose tissue $(\mathrm{p}=0.0400)$ and epididymal adipose tissue $(\mathrm{p}=0.0442)$. The gene expression of the only known extra-cellular efflux transporter $Z n T 1$ as well as the gene expression of $Z n T 6$ and $Z n T 7$ were unaffected by the induction of diabetes as were ZIP3, ZIP11, ZIP13, and ZIP14.

No significant differences were seen when comparing the three

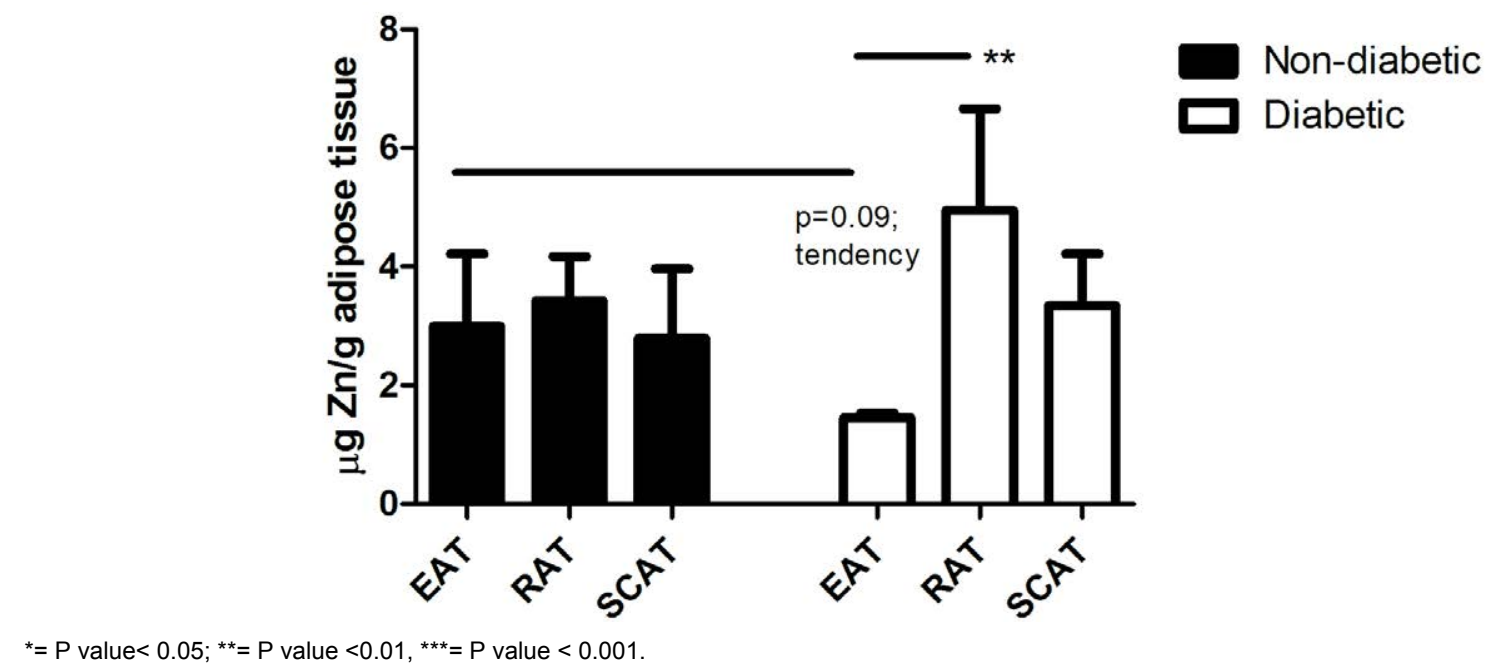

Figure 1: Zinc content in adipose tissue. The content of zinc in epididymal adipose tissue (EAT), retroperitoneal adipose tissue (RAT) and subcutaneous adipose tissue (SCAT) from non-diabetic animals (non-diabetic) and diabetic animals (diabetic). Results are expressed as $\mu \mathrm{g}$ zinc/g adipose tissue ( $\mu \mathrm{g} \mathrm{Zn} / \mathrm{g}$ adipose tissue).

\begin{tabular}{|c|c|c|c|c|c|c|}
\hline \multirow{2}{*}{$\begin{array}{c}\text { Trace } \\
\text { element }\end{array}$} & \multicolumn{2}{|c|}{ Epididymal adipose tissue } & \multicolumn{2}{|c|}{ Retroperitoneal adipose tissue } & \multicolumn{2}{|c|}{ Subcutaneous adipose tissue } \\
\hline & ND & D & ND & D & ND & D \\
\hline $\mathrm{Zn}$ & $3.0( \pm 1.2)$ & $1.4( \pm 0.1)$ & $3.4( \pm 0.7)$ & $\begin{array}{c}5.0( \pm 1.7) \\
\text { ** Compared with epididymal } \\
\text { adipose tissue from D. }\end{array}$ & $2.8( \pm 1.2)$ & $3.3( \pm 0.9)$ \\
\hline $\mathrm{Cu}$ & $2.7( \pm 4.9)$ & $0.4( \pm 0.2)$ & $0.9( \pm 0.6)$ & $1.0( \pm 0.6)$ & $1.4( \pm 1.8)$ & $2.7( \pm 3.5)$ \\
\hline $\mathrm{Fe}$ & $8.9( \pm 2.2)$ & $\begin{array}{c}12.4( \pm 1.6) \\
* \text { Compared with epididymal } \\
\text { adipose tissue from ND. }\end{array}$ & $26.8( \pm 23.8)$ & $19.6( \pm 12.6)$ & $21.6( \pm 15.4)$ & $19.4( \pm 15.7)$ \\
\hline $\mathrm{Cu} / \mathrm{Zn}$ ratio & $0.57( \pm 0.45)$ & $0.27( \pm 0.09)$ & $0.31( \pm 0.22)$ & $0.21( \pm 0.09)$ & $0.41( \pm 0.14)$ & $0.60( \pm 0.47)$ \\
\hline
\end{tabular}

$\mathrm{ND}=$ Non-diabetic animals. $\mathrm{D}=$ Diabetic animals.

${ }^{*}=\mathrm{P}$ value $<0.05 ;{ }^{* *}=\mathrm{P}$ value $<0.01,{ }^{* * *}=\mathrm{P}$ value $<0.001$

Table 2: Content of zinc $(\mathrm{Zn})$, iron (Fe), copper $(\mathrm{Cu})$ and the calculated $\mathrm{Cu} / \mathrm{Zn}$ ratio in adipose tissue from $P$. obesus. Contents are shown as $\mu \mathrm{g}$ trace element/g adipose tissue \pm std. deviation. 
Citation: Maxel T, Pold R, Larsen A, Pedersen SB, Carlson D, et al. (2015) Dysregulation of Zinc and Iron Balance in Adipose Tissue from Diabetic Sand Rats (Psammomys obesus). J Diabetes Metab 6: 497. doi:10.4172/2155-6156.1000497

Page 5 of 11

adipose tissues in diabetic animals. In non-diabetic animals, however, a higher gene expression of ZIP6 was found in subcutaneous adipose tissue compared with epididymal adipose tissue $(\mathrm{p}=0.0247)$.

The gene expression patterns of the measured $Z n T$ s are shown in Figure 2 and the gene expression patterns of the measured ZIPs in Figure 3.

In conclusion, altered gene expression of zinc transporters as a result of T2D was found only in visceral adipose tissue, especially retroperitoneal adipose tissue. Of the investigated zinc transporters; three zinc transporters were transcriptionally down-regulated in retroperitoneal adipose tissue $(Z n T 9, Z I P 8, Z I P 9)$, whereas one (ZIP6) was up-regulated in both retroperitoneal adipose tissue and epididymal adipose tissue.

Reduced gene expression of metabolic parameters in diabetic animals vs. non-diabetic animals - different patterns in visceral and subcutaneous adipose tissue

$L P L, I D E, P P A R \gamma, H S L$, and leptin were uniformly expressed in subcutaneous and visceral (retroperitoneal and epididymal) adipose
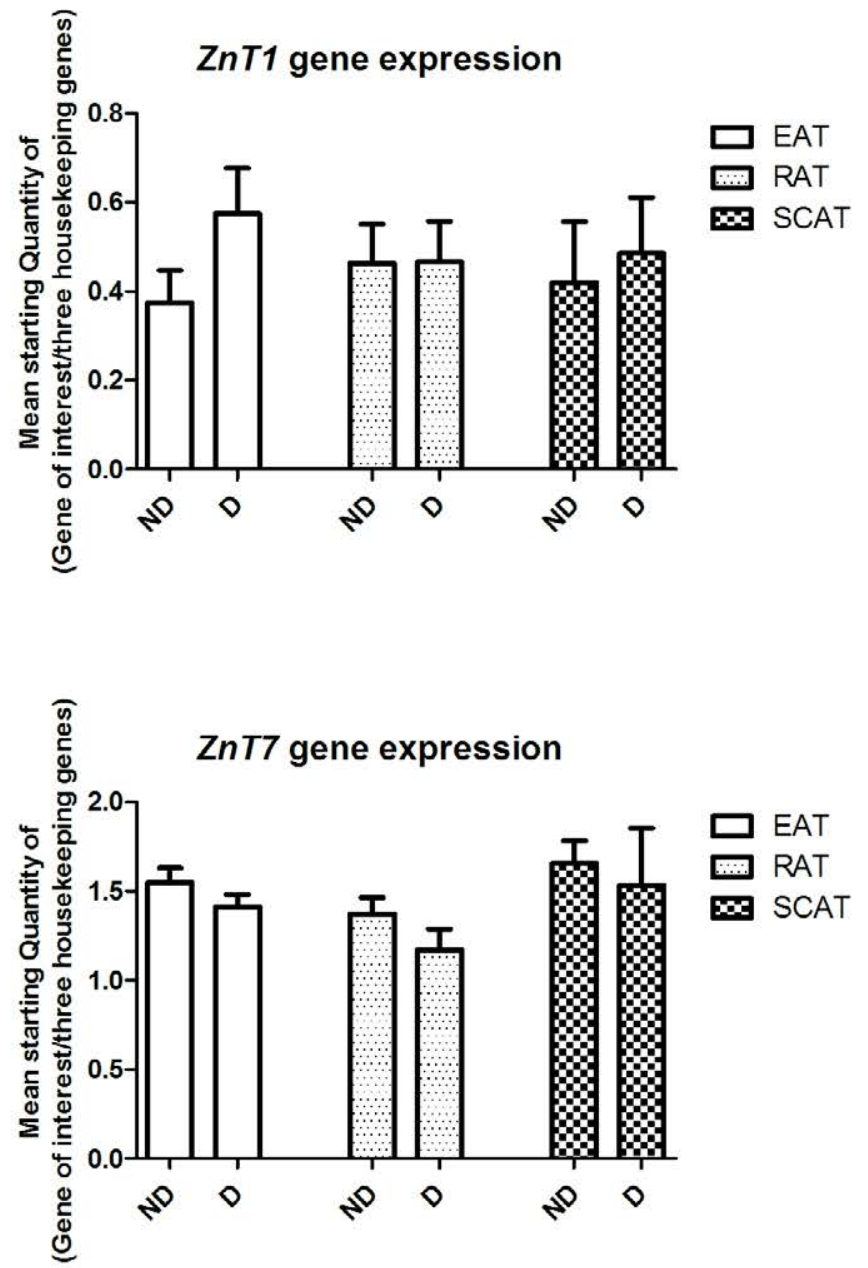

tissue in both diabetic and non-diabetic $P$. obesus. However, comparing diabetic and non-diabetic animals - several differences in metabolic parameters were observed.

Compared to non-diabetic controls, induction of diabetes resulted in a reduced gene expression of $L P L$ in all 3 types of adipose tissue; epididymal adipose tissue $(\mathrm{p}=0.0169)$, retroperitoneal adipose tissue $(\mathrm{p}=0.0061)$, and subcutaneous adipose tissue $(\mathrm{p}=0.0178)$.

In addition, the gene expression of IDE was reduced in retroperitoneal adipose tissue $(\mathrm{p}=0.0098)$, whereas $P P A R \gamma$ was reduced in subcutaneous adipose tissue $(\mathrm{p}=0.0041)$ but not in other types of adipose tissue. No changes were observed for HSL or leptin.

The gene expressions of the various metabolic markers are shown in Figure 4.

Zinc concentrations correlated with gene expression of zinc transporter protein ZIP6 in diabetic animals

As the zinc transporters showed a high degree of regulation in visceral adipose tissue, we correlated the $\mathrm{Zn}$ levels with the gene expression level of ZIP6, a plasma membrane located zinc transporter.
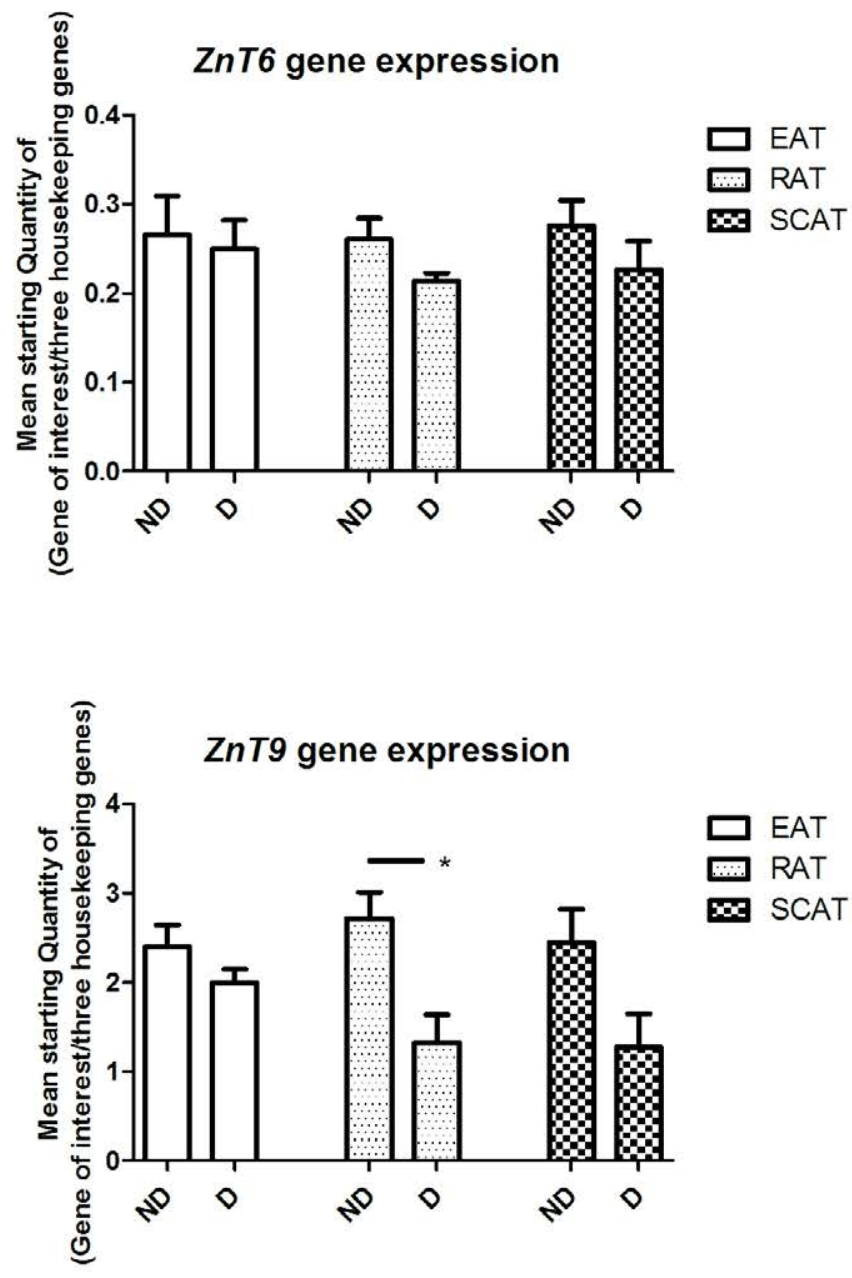

Figure 2: Gene expressions of ZnTs in adipose tissue from non-diabetic animals and diabetic animals. Gene expressions of ZnT1, ZnT6, ZnT7, and ZnT9 in epididymal adipose tissue (EAT), retroperitoneal adipose tissue (RAT), and subcutaneous adipose tissue (SCAT) in non-diabetic animals (ND) and diabetic animals (D). 

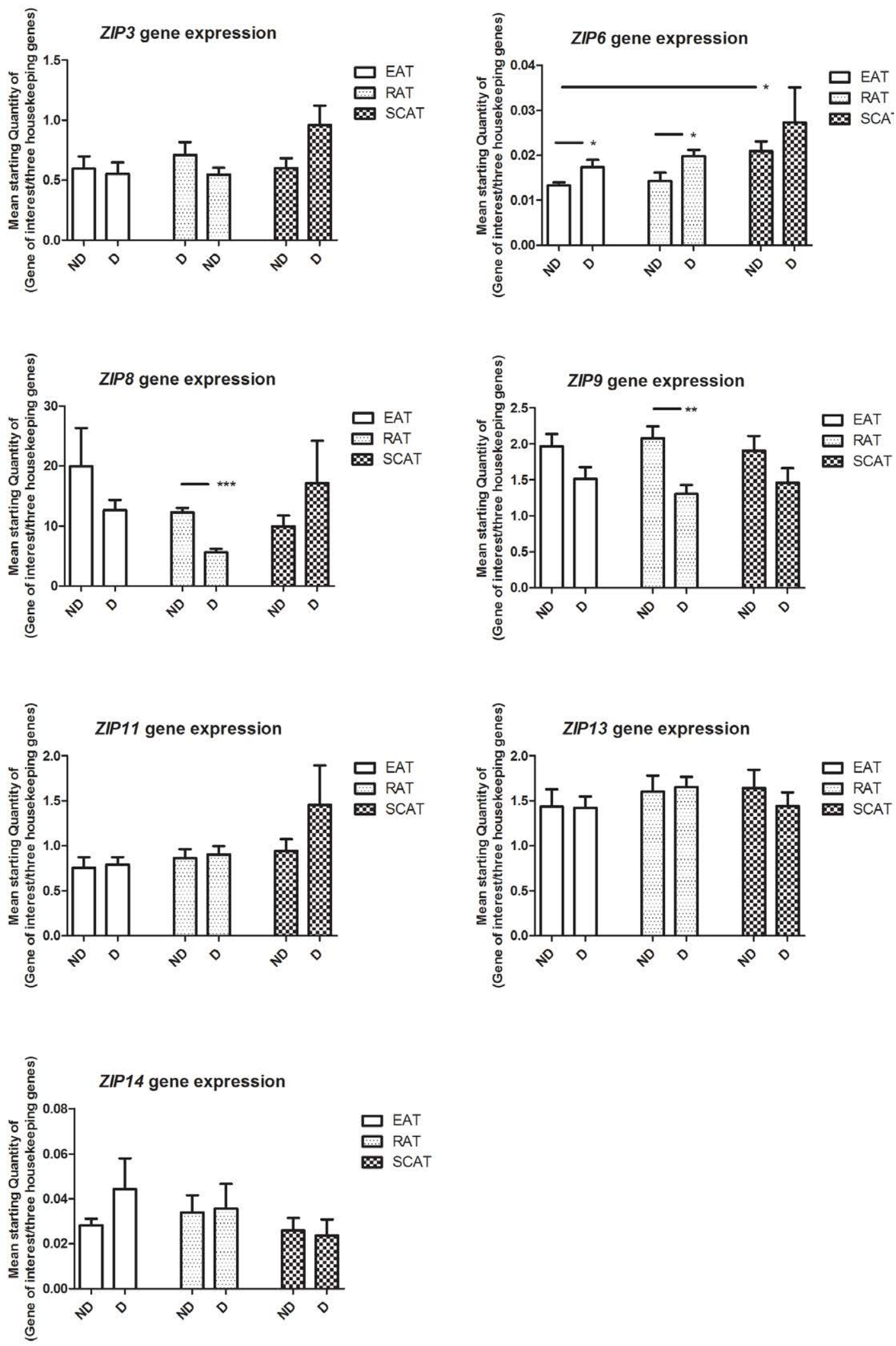

${ }^{*}=\mathrm{P}$ value $<0.05 ;{ }^{* *}=\mathrm{P}$ value $<0.01,{ }^{* * *}=\mathrm{P}$ value $<0.001$

Figure 3: Gene expressions of ZIPs in adipose tissue from non-diabetic animals and diabetic animals. Gene expressions of ZIP3, ZIP6, ZIP8, ZIP9, ZIP11, ZIP13, and ZIP14 in epididymal adipose tissue (EAT), retroperitoneal adipose tissue (RAT), and subcutaneous adipose tissue (SCAT) in non-diabetic animals (ND) and diabetic animals (D). 

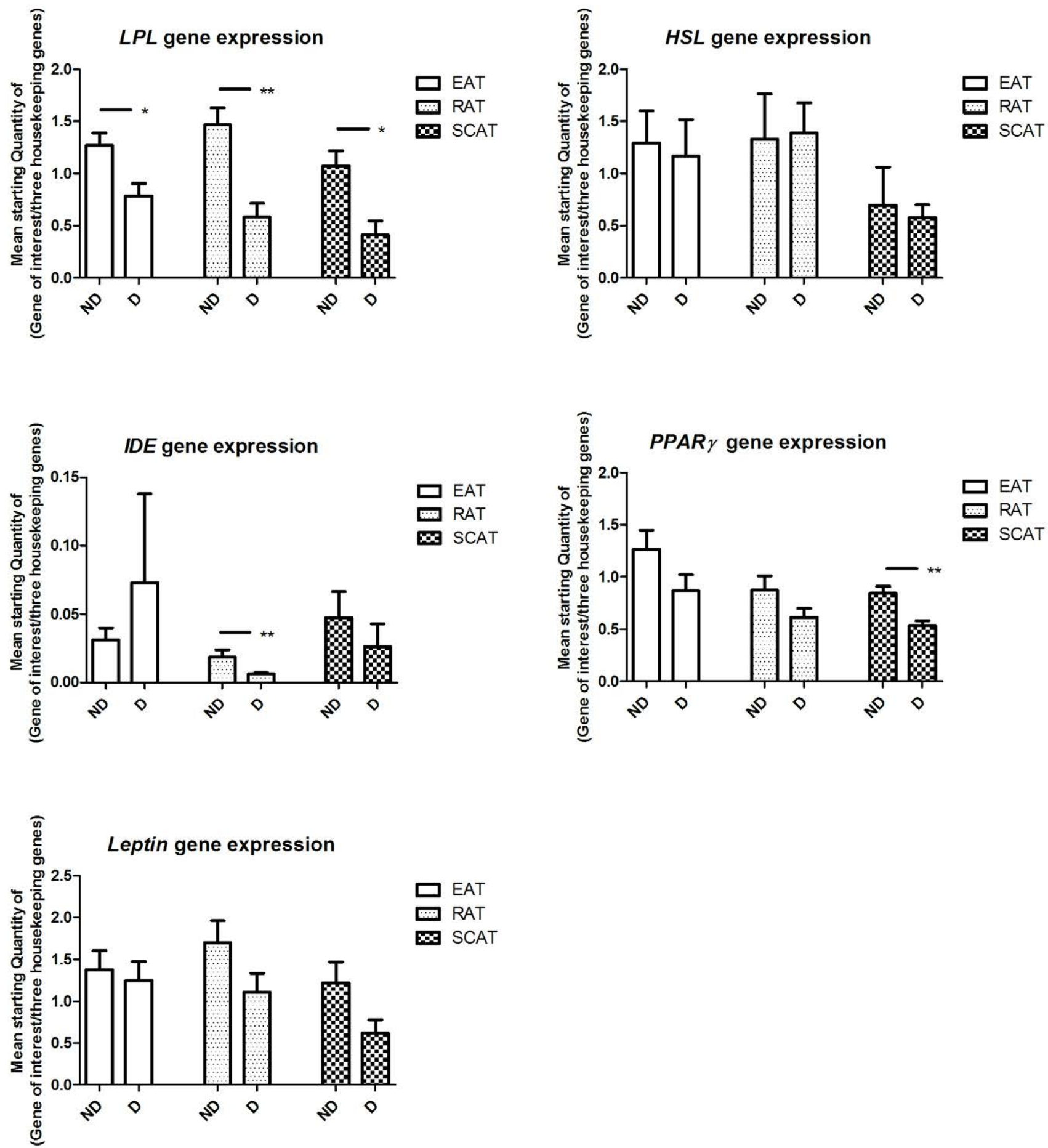

${ }^{*}=\mathrm{P}$ value $<0.05 ;{ }^{* *}=\mathrm{P}$ value $<0.01,{ }^{* * *}=\mathrm{P}$ value $<0.001$

Figure 4: Gene expressions of different metabolic parameters in adipose tissue from non-diabetic and diabetic animals. The gene expressions of lipoprotein lipase $(L P L)$, hormone sensitive lipase (HSL), insulin degrading enzyme (IDE), peroxisome proliferator-activated receptor gamma (ppary) and leptin in epididymal adipose tissue (EAT), retroperitoneal adipose tissue (RAT), and subcutaneous adipose tissue (SCAT) in non-diabetic animals (ND) and diabetic animals (D).

A significant correlation was found between the gene expression of ZIP6 and the $\mathrm{Zn}$ content in retroperitoneal adipose tissue in the diabetic animals $(\mathrm{r}=0.91, \mathrm{p}=0.01)$. The correlation was not present in the nondiabetic animals neither in epididymal adipose tissue (Table 3 ).
Iron levels correlated with an altered gene expression of $I D E$ and PPAR $y$

A standard Pearson correlation was used as a measurement of a possible linear correlation between the investigated parameters i.e. the 


\begin{tabular}{|c|c|c|c|c|}
\hline & \multicolumn{2}{|c|}{$\begin{array}{l}\text { Epididymal } \\
\text { adipose tissue }\end{array}$} & \multicolumn{2}{|c|}{$\begin{array}{l}\text { Retroperitoneal } \\
\text { adipose tissue }\end{array}$} \\
\hline & ND & D & ND & D \\
\hline $\begin{array}{l}\text { Correlation between zinc transporter } \\
\text { ZIP6 and } Z n \text { content }\end{array}$ & $\begin{array}{l}r=-0.22 \\
p=0.68\end{array}$ & $\begin{array}{l}r=0.37 \\
p=0.47\end{array}$ & $\begin{array}{l}r=-0.66 \\
p=0.15\end{array}$ & $\begin{aligned} r & =0.91 \\
p & =0.01\end{aligned}$ * \\
\hline
\end{tabular}

Table 3. Correlations between zinc ( $\mathrm{Zn})$ content and the gene expression of zinc transporter ZIP6 in adipose tissue from $P$. obesus. ND= Non-diabetic animals. $D=$ Diabetic animals. Correlations were performed using Pearson correlations. Pearsons $r$ value and $p$-value are indicated in the table.

\begin{tabular}{|c|c|c|}
\hline & Fe content & Zn content \\
\hline \multirow{2}{*}{ IDE } & $r=0.87$ & $r=0.38$ \\
& $p=0.02^{*}$ & $p=0.46$ \\
\hline \multirow{2}{*}{ PPARY } & $r=0.90$ & $r=0.32$ \\
& $p=0.01^{*}$ & $p=0.53$ \\
\hline \multirow{2}{*}{ LPL } & $r=0.22$ & $r=-0.28$ \\
& $p=0.67$ & $p=0.59$ \\
\hline \multirow{2}{*}{ LSL } & $r=0.78$ & $r=-0.50$ \\
& $p=0.06$ & $p=0.31$ \\
\hline \multirow{2}{*}{ Leptin } & $r=0.60$ & $r=-0.54$ \\
& $p=0.21$ & $p=0.27$ \\
\hline
\end{tabular}

${ }^{*}=\mathrm{P}$ value $<0.05 ;{ }^{* *}=\mathrm{P}$ value $<0.01,{ }^{* * *}=\mathrm{P}$ value $<0.001$

Table 4: Correlations between metabolic markers and iron and zinc content in epididymal adipose tissue. Correlations of iron ( $\mathrm{Fe})$ and zinc $(\mathrm{Zn})$ content with metabolic markers; insulin degrading enzyme (IDE), peroxisome proliferatoractivated receptor gamma (PPARY), lipoprotein lipase ( $L P L)$, hormone sensitive lipase (HSL), and leptin in diabetic animals. Correlations were performed using Pearson correlations. Pearsons $r$ value and $p$-value are indicated in the table.

gene expression of selected genes and the actual concentrations of $\mathrm{Fe}$ and $\mathrm{Zn}$. In this way correlating the changes observed of Fe in epididymal adipose tissue from diabetic animals with the measured metabolic markers showed a significant positive correlation with $I D E(\mathrm{r}=0.87$, $\mathrm{p}=0.02)$ and $P P A R \gamma(\mathrm{r}=0.90, \mathrm{p}=0.01)$. No significant correlations were found in regard of $L P L, H S L$, or leptin and neither when correlating $\mathrm{Zn}$ with the metabolic markers (Table 4).

\section{Discussion}

In the present study we examined the multi-factorial animal model of T2D, P. obesus, for the first time investigating if the zinc and iron levels in adipose tissue of these animals respond to the development of metabolically elicited diabetes in the genetically susceptible animals. The development of T2D in P. obesus is comparable with human T2D in many ways: it is partly diet-induced but shows a genetic component, insulin resistance is present in muscle tissue, and many of the disease stages are similar, making this model of particular interest for the investigation of obesity-induced T2D $[42,43]$.

We found evidence of changes within the total content of Fe. These changes correlated with an increased gene expression of the metabolic markers IDE and PPAR $\gamma$, supporting other reports that iron participates in adipose tissue metabolism [44]. Intracellular signs of an altered zinc homeostasis were seen, as gene expression patterns of several zinc transporters of both the ZnT and ZIP family were affected. In addition, significant differences in total zinc content were seen between various types of adipose tissue in the diabetic animals. The changes observed, were found in retroperitoneal and epididymal adipose tissue, thus indicating that intracellular zinc signalling could play a role in the development of metabolic disease in visceral fat [3].

The fact that intracellular zinc homeostasis is affected in adipose tissue upon weight gain has previously been shown by Smidt and coworkers. The study investigated human adipose tissue from obese individuals, and a consistent transcriptional down-regulation of zinc transporters of both families (ZnTs and ZIPs) were found in adipose tissue from obese individuals compared to lean controls [31]. The present study shows that an altered regulation in the gene expression of zinc transporters is not only found in obesity but also in T2D.

We found a transcriptional down-regulation of ZnT9, ZIP9, and ZIP8 in retroperitoneal adipose tissue. This expression pattern of ZIP8 is consistent with the findings of Smidt and co-workers, whereas it is the first time that ZnT9 and ZIP9 have been investigated in adipose tissue.

Genetic variations of ZIP8 have previously been associated with obesity, and the present study indicates that regulation of ZIP8 gene expression could be an upstream event of zinc dyshomeostasis in metabolically-stressed adipocytes [45].

In addition to ZIP8, the gene expression of ZIP6 also responds to metabolic changes in $P$. Obesus, being up-regulated in visceral adipose tissue from diabetic animals. As ZIP6 is primarily located at the plasma membrane, we correlated the zinc level in visceral adipose tissue with ZIP6 gene expression, and found a significant positive correlation in the retroperitoneal adipose tissue from diabetic animals, implying a physiological consequence of the diabetes-induced up-regulation of ZIP6 gene expression on the Zn level. We have previously found ZIP6 to be down-regulated in obese women compared to lean controls [31]. This study did however not include diabetic individuals. However, it cannot be excluded that differences between humans and other species also contribute to the difference in ZIP6 gene regulation.

In this study, we found that whereas the non-diabetic animals showed equal zinc distribution between the three fat depots, the diabetic animals had a significantly lower zinc level in epididymal adipose tissue compared to retroperitoneal adipose tissue. Retroperitoneal and epididymal adipose tissue are however metabolically different visceral adipose depots, as epididymal adipose tissue is likely to be more affected by reproductive hormones.

The intracellular zinc pool is a mixture of both free and protein bound zinc. The total amount of intracellular zinc reaches micro-molar concentration levels whereas free intracellular zinc is found only in pico-molar concentrations. This reflects the high amount of proteinbound zinc. Accordingly, alterations in protein-bound zinc might camouflage small alterations in free zinc when comparing diabetic and non-diabetic sand rats [46]. Similarly, as many proteins harbour zinc, quantitative measurements of protein-bound zinc might disguise different patterns of protein expression. In general, zinc deficiency needs to be quite severe before any actual changes in mineral content are detected in various tissues [47]. As the free zinc is as low as picomolar concentrations, even small alterations in ambient zinc content could be reflected by intracellular zinc dys-homeostasis and hence dysfunctional intracellular zinc signalling, and at least in vitro changes in ambient zinc are directly reflected in the intracellular zinc regulation [48].

Supporting this, we found that a type 2 diabetic environment leads to a transcriptional down-regulation of $Z n T 9, Z I P 8$, and ZIP9 in visceral adipose tissue, as well as a transcriptional up-regulation of ZIP6. Whether this pattern constitutes the complete intracellular response to the altered mineral status of the diabetes prone $P$. Obesus remains to be seen. As the genome of this animal model is currently not sequenced, all primers for the present study had to be designed from scratch based on primers from other animal models and we still need to establish if any of the primers currently not functioning does in fact 
reflect that one or more zinc transporters of either the ZnT or the ZIP family are not expressed in P. obesus.

An altered cellular zinc homeostasis due to alterations in the expression of zinc transporters in T2D could have several adverse metabolic consequences if reflected by altered protein expression. Both zinc accumulation and zinc deprivation may result in apoptosis and hence loss of beta cell mass. Moreover zinc deficiency within the cell is known to cause oxidative damage [49] which could further accelerate beta-cell death.

Metabolic intracellular regulation is also zinc dependent, as zinc shows many insulinomimetic properties in adipose tissue. Zinc thus stimulates glucose uptake and lipogenesis, and inhibits the release of free fatty acids through its stimulation of the insulin signalling pathway [9]. Changes in the gene expression of $Z I P$ and $Z n T$ transporters could thereby induce oxidative or apoptotic damage within the cell as well as induce an altered insulin signalling affecting the metabolic regulation of the adipocyte.

We also saw a significant down-regulation of ZIP9 gene expression in diabetic animals compared to non-diabetic animals. At present, little is known about ZIP9. However, as ZIP9 is localized in the transGolgi network supposedly transporting zinc from Golgi to the cytosol, it could be speculated that the down-regulation of this transporter could serve as a way of ensuring sufficient presence of zinc in the Golgi apparatus [50-55].

Induction of diabetes was also reflected in a down-regulation of $Z n T 9$ gene expression in retroperitoneal adipose tissue. Not much is known about the zinc transporting functions of ZnT9 besides its localization in the cytoplasm in human cells [56].

The altered metabolic activity in the high-calorie challenged diabetes-prone P.obesus was also reflected in signs of a reduced insulin sensitivity of the adipose tissue. The gene expression of $I D E$ was hence reduced in retroperitoneal adipose tissue in diabetic animals compared to control animals. Down-regulation of IDE indicates elevated insulin levels signifying an insulin resistance in the tissue [57]. Although, IDE belongs to a family of zinc-metalloproteases and is regulated by the $\mathrm{Zn}$ level present in the tissue, IDE gene expression was not directly correlated to zinc concentrations in this study [18]. Instead, we found a significant correlation between $I D E$ and iron homeostasis i.e. high iron concentration correlated with a high level of IDE gene expression, indicating an increased insulin metabolism in iron-rich environments in the diabetic animals.

The high iron content found in the present study is in line with recent discovery done by Orr and co-workers also finding an accumulation of iron in epididymal adipose tissue from mice fed a high-energy diet [58]. Our study is the first to show that this iron accumulation seems to be specific for epididymal adipose tissue when comparing epididymal, retroperitoneal, and subcutaneous adipose tissues. The iron accumulation in epididymal adipose tissue likely induces impaired insulin signalling and insulin resistance as shown in C57BL/6 mice fed an iron-enriched diet [44].

The content of iron in epididymal adipose tissue was also positively correlated with the gene expression of PPAR $\gamma$ [18]. PPAR $\gamma$ is the main regulator of adipogenesis and serves as a transcription factor controlling genes involved in both lipid metabolism and adipogenesis $[59,60]$. The low PPARy gene expression level in subcutaneous fat seen in the diabetic animals could be an indication of decreased adipogenesis in these depots. The ability to form new adipocytes in response to excess energy intake is hypothesized to be important for a healthy adipose tissue expansion, as expansion which is primarily driven by enlargement of the individual adipocytes results in insulin resistance and hypoxia [61].

In conclusion; this study supports the hypothesis that dysregulation of mineral homeostasis is part of the pathology of T2D, at least when induced by a combination of genetic and dietary factors, emphasizing the role of zinc and iron in the function of adipose tissue in general and in visceral adipose depots in particular. Diabetic animals displayed increased iron concentration in adipose tissue which directly correlated with altered expression of IDE and PPAR $\gamma$. Alterations in PPARy gene expression also support the hypothesis that a downregulation of subcutaneous adipogenesis could participate in metabolic stress in the P. obesus model. Moreover, shifts in total zinc between epididymal and retroperitoneal visceral adipose depots, accompanied by changes in expression of zinc transporters, indicate that changes in intracellular zinc homeostasis participate in altered adipocyte functioning during metabolic stress.

\section{Acknowledgements}

The authors thank Lisbet Thomassen and Jens Hansen-Møller from Department of Animal Science, Aarhus University, Bodil Pihlkjær and Hans Brix from the institute of Biomedicine, Plant Biology, Aarhus University for helping with the measurements of trace elements. We thank the technical staff at our department, especially Karen Skjødt Sørensen and Pia Hornbek, for expert help in the laboratory and good advices. Funding for this study was provided by the Faculty of Health Science, Aarhus University, The AP. Møller and Wife Chastine Mc-Kinney Moellers Foundation, and The Aase and Ejnar Danielsen Foundation. None of the funding resources had any involvement in the design, writing or decisions regarding the study. All authors read, revised and approved the final manuscript. The authors declare that they have no conflict of interest.

\section{References}

1. Kahn SE, Hull RL, Utzschneider KM (2006) Mechanisms linking obesity to insulin resistance and type 2 diabetes. Nature 444: 840-846.

2. Raz I, Eldor R, Cernea S, Shafrir E (2005) Diabetes: insulin resistance and derangements in lipid metabolism. Cure through intervention in fat transport and storage. Diabetes Metab Res Rev 21: 3-14.

3. Fruhbeck G (2008) Overview of adipose tissue and its role in obesity and metabolic disorders. Methods Mol Biol 456: 1-22.

4. Garcia OP, Long KZ, Rosado JL (2009) Impact of micronutrient deficiencies on obesity. Nutr Rev 67: 559-572.

5. de Luis DA, Pacheco D, Izaola O, Terroba MC, Cuellar L, et al. (2013) Micronutrient status in morbidly obese women before bariatric surgery. Surg Obes Relat Dis 9: 323-327

6. Viktorinova A, Toserova E, Krizko M, Durackova Z (2009) Altered metabolism of copper, zinc, and magnesium is associated with increased levels of glycated hemoglobin in patients with diabetes mellitus. Metabolism 58: 1477-1482.

7. Suliburska J, Bogdanski P, Pupek-Musialik D, Krejpcio Z (2011) Dietary intake and serum and hair concentrations of minerals and their relationship with serum lipids and glucose levels in hypertensive and obese patients with insulin resistance. Biol Trace Elem Res 139: 137-150.

8. Simcox JA, McClain DA (2013) Iron and diabetes risk. Cell Metab 17: 329-341

9. Yoshikawa Y, Ueda E, Kojima Y, Sakurai H (2004) The action mechanism of zinc(II) complexes with insulinomimetic activity in rat adipocytes. Life Sci 75 741-751.

10. Kazi TG, Afridi HI, Kazi N, Jamali MK, Arain MB, et al. (2008) Copper chromium, manganese, iron, nickel, and zinc levels in biological samples of diabetes mellitus patients. Biol Trace Elem Res 122: 1-18.

11. Zheng Y, Li XK, Wang Y, Cai L (2008) The role of zinc, copper and iron in the pathogenesis of diabetes and diabetic complications: therapeutic effects by chelators. Hemoglobin 32: 135-145.

12. Al-Maroof RA, Al-Sharbatti SS (2006) Serum zinc levels in diabetic patients and 
Citation: Maxel T, Pold R, Larsen A, Pedersen SB, Carlson D, et al. (2015) Dysregulation of Zinc and Iron Balance in Adipose Tissue from Diabetic Sand Rats (Psammomys obesus). J Diabetes Metab 6: 497. doi:10.4172/2155-6156.1000497

effect of zinc supplementation on glycemic control of type 2 diabetics. Saudi Med J 27: 344-350.

13. Jansen J, Karges W, Rink L (2009) Zinc and diabetes--clinical links and molecular mechanisms. J Nutr Biochem 20: 399-417.

14. Quraishi I, Collins S, Pestaner JP, Harris T, Bagasra O (2005) Role of zinc and zinc transporters in the molecular pathogenesis of diabetes mellitus. Med Hypotheses 65: 887-892.

15. Chimienti F, Devergnas S, Pattou F, Schuit F, Garcia-Cuenca R, et al. (2006) In vivo expression and functional characterization of the zinc transporter ZnT8 in glucose-induced insulin secretion. J Cell Sci 119: 4199-4206.

16. Rungby J (2010) Zinc, zinc transporters and diabetes. Diabetologia 53: 1549 1551.

17. Mocchegiani E, Giacconi R, Malavolta M (2008) Zinc signalling and subcellular distribution: emerging targets in type 2 diabetes. Trends Mol Med 14: 419-428.

18. Costarelli L, Muti E, Malavolta M, Cipriano C, Giacconi R, et al. (2010) Distinctive modulation of inflammatory and metabolic parameters in relation to zinc nutritional status in adult overweight/obese subjects. J Nutr Biochem 21: $432-437$.

19. Chimienti F, Devergnas S, Favier A, Seve M (2004) Identification and cloning of a beta-cell-specific zinc transporter, $\mathrm{ZnT}-8$, localized into insulin secretory granules. Diabetes 53: 2330-2337.

20. Wijesekara N, Dai FF, Hardy AB, Giglou PR, Bhattacharjee A, et al. (2010) Beta cell-specific Znt8 deletion in mice causes marked defects in insulin processing, crystallisation and secretion. Diabetologia 53: 1656-1668.

21. Sladek R, Rocheleau G, Rung J, Dina C, Shen L, et al. (2007) A genome-wide association study identifies novel risk loci for type 2 diabetes. Nature 445: 881 885

22. Flannick J, Thorleifsson G, Beer NL, Jacobs SB, Grarup N, et al. (2014) Lossof-function mutations in SLC30A8 protect against type 2 diabetes. Nat Genet 46: 357-363.

23. Huang L, Yan M, Kirschke CP (2010) Over-expression of ZnT7 increases insulin synthesis and secretion in pancreatic beta-cells by promoting insulin gene transcription. Exp Cell Res 316: 2630-2643

24. Smidt K, Jessen N, Petersen AB, Larsen A, Magnusson N, et al. (2009) SLC30A3 responds to glucose- and zinc variations in beta-cells and is critical for insulin production and in vivo glucose-metabolism during beta-cell stress. PLoS One 4: e5684.

25. Maret W (2011) Metals on the move: zinc ions in cellular regulation and in the coordination dynamics of zinc proteins. Biometals 24: 411-418.

26. Harris ED (2002) Cellular transporters for zinc. Nutr Rev 60: 121-124.

27. Jenkitkasemwong S, Wang CY, Mackenzie B, Knutson MD (2012) Physiologic implications of metal-ion transport by ZIP14 and ZIP8. Biometals 25: 643-655.

28. Girijashanker K, He L, Soleimani M, Reed JM, Li H, et al. (2008) Slc39a14 gene encodes ZIP14, a metal/bicarbonate symporter: similarities to the ZIP8 transporter. Mol Pharmacol 73: 1413-1423.

29. Jeong J, Eide DJ (2013) The SLC39 family of zinc transporters. Mol Aspects Med 34: 612-619.

30. Pinilla-Tenas JJ, Sparkman BK, Shawki A, Illing AC, Mitchell CJ, et al. (2011) Zip14 is a complex broad-scope metal-ion transporter whose functional properties support roles in the cellular uptake of zinc and nontransferrin-bound iron. Am J Physiol Cell Physiol 301: 862-871.

31. Smidt K, Pedersen SB, Brock B, Schmitz O, Fisker S, et al. (2007) Zinctransporter genes in human visceral and subcutaneous adipocytes: lean versus obese. Mol Cell Endocrinol 264: 68-73.

32. Pinhas-Hamiel O, Newfield RS, Koren I, Agmon A, Lilos P, et al. (2003) Greater prevalence of iron deficiency in overweight and obese children and adolescents. Int J Obes Relat Metab Disord 27: 416-418.

33. Yanoff LB, Menzie CM, Denkinger B, Sebring NG, McHugh T, et al. (2007) Inflammation and iron deficiency in the hypoferremia of obesity. Int $\mathrm{J}$ Obes (Lond) 31: 1412-1419.

34. Sonnweber T, Ress C, Nairz M, Theurl I, Schroll A, et al. (2012) High-fat diet causes iron deficiency via hepcidin-independent reduction of duodenal iron absorption. J Nutr Biochem 23: 1600-1608.
35. Becker C, Orozco M, Solomons NW, Schumann K (2014) Iron metabolism in obesity: How interaction between homoeostatic mechanisms can interfere with their original purpose. Part I: Underlying homoeostatic mechanisms of energy storage and iron metabolisms and their interaction. J Trace Elem Med Biol S0946-672X(14)00191-6.

36. Knutson MD, Oukka M, Koss LM, Aydemir F, Wessling-Resnick M (2005) Iron release from macrophages after erythrophagocytosis is up-regulated by ferroportin 1 overexpression and down-regulated by hepcidin. Proc Natl Acad Sci U S A 102: 1324-1328.

37. Cairo G, Recalcati S, Montosi G, Castrusini E, Conte D, et al. (1997) Inappropriately high iron regulatory protein activity in monocytes of patients with genetic hemochromatosis. Blood 89: 2546-2553.

38. Liuzzi JP, Aydemir F, Nam H, Knutson MD, Cousins RJ (2006) Zip14 (Slc39a14) mediates non-transferrin-bound iron uptake into cells. Proc Natl Acad Sci U S A 103: 13612-13617.

39. Mackenzie B, Ujwal ML, Chang MH, Romero MF, Hediger MA (2006) Divalent metal-ion transporter DMT1 mediates both $\mathrm{H}+-$-coupled $\mathrm{Fe} 2+$ transport and uncoupled fluxes. Pflugers Arch 451: 544-558.

40. Smidt K, Wogensen L, Brock B, Schmitz O, Rungby J (2006) Real-time PCR housekeeping genes in the INS-1E beta-cell line. Horm Metab Res 38: 8-11.

41. Vandesompele J, De PK, Pattyn F, Poppe B, Van RN, et al. (2002) Accurate normalization of real-time quantitative RT-PCR data by geometric averaging of multiple internal control genes. Genome Biol 3: RESEARCH0034.

42. Kaiser N, Cerasi E, Leibowitz G (2012) Diet-induced diabetes in the sand rat (Psammomys obesus). Methods Mol Biol 933: 89-102.

43. Shafrir E, Ziv E (1998) Cellular mechanism of nutritionally induced insulin resistance: the desert rodent Psammomys obesus and other animals in which insulin resistance leads to detrimental outcome. J Basic Clin Physiol Pharmaco 9: 347-385.

44. Dongiovanni P, Ruscica M, Rametta R, Recalcati S, Steffani L, et al. (2013) Dietary iron overload induces visceral adipose tissue insulin resistance. Am J Pathol 182: 2254-2263

45. Speliotes EK, Willer CJ, Berndt SI, Monda KL, Thorleifsson G, et al. (2010) Association analyses of 249,796 individuals reveal 18 new loci associated with body mass index. Nat Genet 42: 937-948.

46. Maret W (2009) Molecular aspects of human cellular zinc homeostasis: redox control of zinc potentials and zinc signals. Biometals 22: 149-157.

47. Brown KH, Wuehler SE, Peerson JM (2001) The importance of zinc in human nutrition and estimation of the global prevalence of zinc deficiency. Specia Issue on Recent Intervention Trials with Zinc: Implications for Programs and Research 22: 113

48. Nygaard SB, Larsen A, Knuhtsen A, Rungby J, Smidt K (2014) Effects of zinc supplementation and zinc chelation on in vitro beta-cell function in INS-1E cells. BMC Res Notes 7: 84

49. Plum LM, Rink L, Haase H (2010) The essential toxin: impact of zinc on human health. Int J Environ Res Public Health 7: 1342-1365

50. Osborn O, Olefsky JM (2012) The cellular and signaling networks linking the immune system and metabolism in disease. Nat Med 18: 363-374.

51. Tchernof A, Despres JP (2013) Pathophysiology of human visceral obesity: an update. Physiol Rev 93: 359-404.

52. Galvez-Peralta M, Wang Z, Bao S, Knoell DL, Nebert DW (2014) TissueSpecific Induction of Mouse ZIP8 and ZIP14 Divalent Cation/Bicarbonate Symporters by, and Cytokine Response to, Inflammatory Signals. Int J Toxicol 33: $246-258$

53. Noh H, Paik HY, Kim J, Chung J (2014) The Alteration of Zinc Transporte Gene Expression Is Associated with Inflammatory Markers in Obese Women Biol Trace Elem 158: 1-8.

54. Matsuura W, Yamazaki T, Yamaguchi-Iwai $Y$, Masuda S, Nagao M, et al. (2009) SLC39A9 (ZIP9) regulates zinc homeostasis in the secretory pathway: characterization of the ZIP subfamily I protein in vertebrate cells. Biosc Biotechnol Biochem 73: 1142-1148.

55. Taniguchi M, Fukunaka A, Hagihara M, Watanabe K, Kamino S, et al.(2013) Essential role of the zinc transporter ZIP9/SLC39A9 in regulating the activations of Akt and Erk in B-cell receptor signaling pathway in DT40 cells. PLoS One 8: e58022. 
Citation: Maxel T, Pold R, Larsen A, Pedersen SB, Carlson D, et al. (2015) Dysregulation of Zinc and Iron Balance in Adipose Tissue from Diabetic Sand Rats (Psammomys obesus). J Diabetes Metab 6: 497. doi:10.4172/2155-6156.1000497

56. Huang L, Tepaamorndech S (2013) The SLC30 family of zinc transporters - a review of current understanding of their biological and pathophysiological roles. Mol Aspects Med 34: 548-560.

57. Farris W, Mansourian S, Chang Y, Lindsley L, Eckman EA, et al. (2003) Insulindegrading enzyme regulates the levels of insulin, amyloid beta-protein, and the beta-amyloid precursor protein intracellular domain in vivo. Proc Natl Acad Sci U S A 100: 4162-4167.

58. Orr JS, Kennedy A, Anderson-Baucum EK, Webb CD, Fordahl SC, et al. (2013) Obesity Alters Adipose Tissue Macrophage Iron Content and Tissue Iron Distribution. Diabetes 63: 421-432.
59. Rosen ED, MacDougald OA (2006) Adipocyte differentiation from the inside out. Nat Rev Mol Cell Biol 7: 885-896.

60. Zieleniak A, Wojcik M, Wozniak LA (2008) Structure and physiological functions of the human peroxisome proliferator-activated receptor gamma. Arch Immuno Ther Exp (Warsz ) 56: 331-345.

61. Sun K, Kusminski CM, Scherer PE (2011) Adipose tissue remodeling and obesity. The Journal of Clinical Investigation 121: 2094-2101. 